\title{
GUIA ÁUDIO TÁTIL EM RESINA DE POLIÉSTER: UMA PROPOSTA DE MODELO DE MATERIAL DIDÁTICO VOLTADO À EDUCAÇÃO DE CEGOS
}

\author{
Audio-tactile guide in polyester resin: a proposal for a didatic material model aiming at blind \\ education
}

https://doi.org/10.18593/eba.24827

Recebido em 20 de julho de 2020 | Aceito em 19 de agosto de 2020

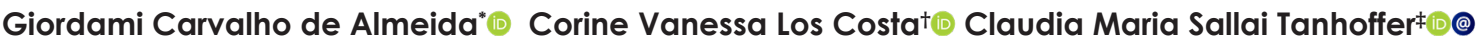 Edson Antonio Tanhoffer $\$$}

\footnotetext{
" Graduado em Ciências Biológicas pela Universidade Federal do Paraná; Mestrando em Ensino pela Universidade Federal do Paraná; Professor Estatutário de Biologia no Estado do Paraná.

† Graduada em Ciências Biológicas pela Universidade Estadual de Ponta Grossa; Mestra em Ensino pela Universidade Federal do Paraná; Professora Estatutária de Biologia no Estado do Paraná.

‡ Doutora em Fisiologia Geral pelo Instituto de Biociências da Universidade de São Paulo; Mestra em Biologia Celular pela Universidade Federal do Paraná; Professora Adjunta IV no Departamento de Fisiologia da Universidade Federal do Paraná.

§ Doutor em Fisiologia Geral pelo Instituto de Biociências da Universidade de São Paulo; Mestre em Biologia Celular pela Universidade Federal do Paraná; Professor Adjunto III no Departamento de Anatomia da Universidade Federal do Paraná.
}

Resumo: $\quad$ Este artigo é a descrição do desenvolvimento de uma metodologia, que se aproxima de um tutorial, para reprodução de materiais que podem ser utilizados como recurso didático em disciplinas cujo o enfoque seja morfologia macroscópica, como Paleontologia ou Anatomia Animal ou Vegetal e Geologia. O processo utiliza borracha de silicone e resina de poliéster para reprodução de peças, e uma interface, via $Q R$-Code, que remete o usuário a uma narração dos conteúdos postada na plataforma digital YouTube. O objetivo foi criar uma abordagem que permita duplicar peças de valor didático, que normalmente não poderiam ser disponibilizadas para manipulação dos estudantes, com maior enfoque na educação para cegos, em que o "tocar significa ver" e que a manipulação é essencial, sendo que a metodologia permite adicionar marcas na textura da peça, como o Alfabeto em Braille. Para tornar o material definitivamente inclusivo, foi propsoto ligar o objeto de interesse a uma plataforma digital, e neste caso, o YouTube via $Q R$-code, em que é postado uma narrativa em áudio. Assim é possível o seu uso em estudos domiciliares ou em metodologias de ensino presencial em que o aluno é o protagonista. Como resultado foi obtido uma cópia de qualidade de um material, normalmente muito caro ou por outros motivos inacessível, cujo os insumos são de baixo custo e adquiridos facilmente, além de poder ser confeccionado nas instalações de um laboratório escolar.

Palavras-chave: Deficientesvisuais. Audio-tátil. QR-Code. YouTube. Tutorial.

@Autor correspondente: Doutora em Fisiologia Geral pelo Instituto de Biociências da Universidade de São Paulo; Mestra em Biologia Celular pela Universidade Federal do Paraná; Professora Adjunta IV no Departamento de Fisiologia da Universidade Federal do Paraná, Setor de Ciências Biológicas, Centro Politécnico, Avenida Cel. Francisco H. dos Santos, 100, Jardim das Américas, 81531-980, Curitiba, Paraná, Brasil; https://orcid.org/0000-0002-4388-3347; sallaicm@ufpr.br 


\begin{abstract}
This article is the description of the development of a methodology, which is similar to a tutorial, for reproducing materials that can be used as a teaching resource in disciplines whose focus is macroscopic morphology, such as Paleontology or Animal or Plant Anatomy and Geology. The process uses silicone rubber and polyester resin to reproduce parts, and an interface, via QR-Code, that takes the user to a narration of the contents posted on the YouTube digital platform. Its objectives were to create an approach that allows duplicating pieces of didactic value, which normally could not be made available for manipulation by students, with a greater focus on education for the blind, in which "touching means seeing" and that manipulation is essential, the methodology allows us to add marks on the texture of the piece, such as the Braille Alphabet. To make the material definitely inclusive, we propose to link the object of interest to a digital platform, and in this case, YouTube via QR-code, where post an audio narrative. Thus, it is possible to use in home studies or in classroom teaching methodologies in which the student is the protagonist. As a result, we obtained a quality copy of a material, usually very expensive or for other inaccessible reasons, whose inputs are low-cost and easily acquired, in addition to being able to be made in the facilities of a school laboratory.

Keywords: Visually impaired. Audio-tactile. QR-Code. YouTube. Tutorial.
\end{abstract}

\section{INTRODUÇÃO}

Um conceito não escrito de deficiência é a incapacidade de um indivíduo competir em igualdade, seja em habilidades físicas, acadêmicas ou laborais. Mas, por vezes, a realidade se impõe e no final nem todos e todas têm as mesmas oportunidades e as possibilidades de sucesso diminuem. Cabe a nós, como membros da sociedade, buscar modos de desfazer ou reduzir obstáculos. A motivação pela democratização do acesso à educação, em particular a educação para cegos, foi a mola que moveu os esforços pela criação e divulgação desta metodologia aparentemente simples, mas é assim que a inclusão deve ser, simples e universal. Um material, ao mesmo tempo cheio de informações e normalmente caro, raro ou mesmo insubstituível que pode ser manipulado sem medo ou mesmo ser levado para estudos domiciliares é um elemento, sem dúvida, capaz de melhorar a qualidade do ensino, em especial nos conteúdos que envolvam morfologia macroscópica. Adicionalmente antevemos um elemento motivador para o estudante e para o docente, criando um ambiente mais fértil para discussão.
A Lei n. 9·394/96 da Lei de Diretrizes e Bases da Educação (LDB), em seu artigo 59, assegura $\mathrm{o}$ atendimento especializado aos estudantes de acordo com suas necessidades especiais, exigindo professores capacitados e metodologias adaptadas. Objetiva-se, com isso, capacitar e inseri-los no mercado de trabalho e prepará-los para a vida em sociedade, com um acesso igualitário aos benefícios de programas sociais, em seu nível de ensino. ${ }^{1}$

Segundo informações obtidas pelo Censo Demográfico de 2010, realizado pelo Instituto Brasileiro de Geografia e Estatística (IBGE), ${ }^{2}$ mais de 45,6 milhões de brasileiros declararam possuir alguma deficiência. Dentre as muitas deficiências citadas, a deficiência visual foi a mais comum, sendo declarada por 35,7 milhões de pessoas, cerca de $18,8 \%$ dos entrevistados. De acordo com dados do Conselho Brasileiro de Oftalmologia (CBO), o Brasil possui aproximadamente $20 \%$ dos estudantes com alterações oftalmológicas diversas que podem ser por hipermetropia, miopia e astigmatismo. Destes, uma pequena porcentagem apresenta grave acuidade visual.

A cegueira é uma deficiência em que ocorre privação do sentido da visão em um ou 
mais olhos, afetando a percepção de cor, tamanho ou forma de objetos. Também influencia a percepção do mundo, pois impossibilita a visualização das informações. Pode ser congênita ou adquirida. A cegueira congênita é aquela em que o indivíduo nasce sem o sentido da visão ou o perde até os cinco anos de idade, ${ }^{3}$ e pode ocorrer durante seu processo de formação intrauterina, por doenças que acometem a gestante como rubéola, doenças que atinjam o aparelho ocular do bebê, por alterações genéticas ou ainda problemas extrauterinos como conjuntivites. ${ }^{4} \mathrm{~A}$ maturação do sentido da visão ocorre de oito a dez anos de idade, sendo mais importante até os cinco primeiros anos, por isso, se houver perda de visão até essa idade, não há retenção de imagens, o que não contribui para a memória visual. ${ }^{3}$ Esta ocorre por meios complexos, em que o cérebro capta as informações sensoriais e armazena primeiramente na memória de curto prazo ou memória de trabalho, podendo permanecer ali por tempo determinado ou ser transferida para a memória operacional ou de longo prazo, aonde permanece por tempo indeterminado. Para que ocorra um aprendizado efetivo, precisa ser reproduzida diversas vezes. ${ }^{3}$

A cegueira adquirida ocorre durante qualquer estágio da vida, de modo distinto à cegueira congênita. A aprendizagem para esses indivíduos será então diferente, visto que, aqueles que nascem cegos nunca terão a experiência da visão e todo aprendizado será baseado nos outros sentidos como tato, audição, olfato e paladar. Já quem perdeu a visão, terá a memória visual como auxílio na aprendizagem, pois podem evocar as formas, cores, objetos que auxiliam na compreensão dos fatos. 5
Existem diferentes tipos e definições de deficiência visual, contudo, para fins educacionais a definição é simples: os cegos são aqueles que necessitam do Braille para estudar e, os de baixa visão, de materiais impressos em letras ampliadas ou auxílio de aparelhos. ${ }^{6}$

Uma forma, talvez a melhor, de incluir os deficientes visuais na sociedade é auxiliando com acesso à educação. A escola deve estar preparada para receber esses estudantes. A realidade, porém, é que muitas ainda não têm condições de receber o estudante cego. Muitos professores ainda não se sentem preparados para recebê-los e as escolas não contam com material didático inclusivo, principalmente pelo custo e disponibilidade no mercado. $^{7}$

As políticas públicas para a educação têm como principal diretriz a inclusão de estudantes com necessidades especiais no ensino regular. ${ }^{8}$ Para isso é preciso que os sistemas de ensino e as escolas construam, de forma coletiva, as condições para atender essa diversidade cada vez maior de estudantes. Nessa perspectiva a escola deve estar preparada para receber estudantes com as mais diferentes deficiências, incluindo as visuais. O artigo 208 da Constituição Federal assegura atendimento educacional especializado aos portadores de deficiência, preferencialmente na rede regular de ensino. A inclusão desses estudantes, bem como o atendimento de suas necessidades especiais, é um grande desafio ao nosso sistema educacional.

No processo de inclusão do deficiente visual é preciso aceitar o estudante como ele é, sem ressaltar suas incapacidades. O sentido da visão é muitas vezes superestimado e sua ausência muitas vezes assume uma dimensão maior do que ela realmente tem. É possível, e 
necessário, que o estudante com deficiência visual tenha acesso a materiais adaptados, adequados aos conhecimentos tátil-cinestésico, auditivo e gustativo. A adequação, especialmente através de materiais gráficos tateáveis e em Braille, contribui para a redução da desigualdade no acesso às informações dos estudantes cegos, em relação aos demais estudantes. ${ }^{9}$

Entre os maiores entraves a este processo inclusivo estão a falta de materiais adaptados aos estudantes com deficiências visuais e a falta de capacitação dos docentes. Nosso laboratório de pesquisa tem atuado na criação e produção de materiais didáticos inclusivos para deficientes visuais a baixo custo. A utilização de materiais didáticos especiais não só se mostra uma facilitadora da construção do conhecimento, como também constitui um eficiente método de inclusão social, tanto no ensino regular como em escolas especiais. ${ }^{10}$

A visão é a via de comunicação mais importante entre o indivíduo e o meio que o cerca. Apesar de nascermos com o aparato físico e cognitivo do sentido da visão, enxergar não é uma habilidade inata, mas sim desenvolvida a partir de experiências visuais vivenciadas ${ }^{11}$ e associadas a informações sensoriais significativas, que serão naturalmente integradas ao cérebro. ${ }^{12}$ A deficiência nesse processo traz prejuízos ao desenvolvimento psicomotor, com repercussões educacionais que podem durar a vida toda. ${ }^{3} \mathrm{~A}$ deficiência visual traz consigo uma redução nas possibilidades de experimentação e afeta o desenvolvimento social, cognitivo e afetivo. Nesse sentido, intervenções educacionais adequadas são necessárias para ampliar essas possibilidades de experimentação possibilitando um maior desenvolvimento das capacidades cognitivas.
Particularmente, o ensino de morfologia macroscópica requer um cuidado especial, sendo um universo amplamente visual. É necessário, então, que o professor seja criativo e use de técnicas diferenciadas para poder ensinar um estudante com deficiência visual. ${ }^{14}$ Se ensinada apenas de forma verbalizada, sem ações práticas, torna-se uma disciplina abstrata para o acadêmico e, portanto, sem sentido e de difícil compreensão para o estudante cego e/ou de baixa visão. ${ }^{15}$ Materiais que estimulem o tato, como em alto relevo ou texturas são facilitadores do processo ensino-aprendizagem. ${ }^{16,17}$

Modelos didáticos que preservem a forma, textura e relevo são utilizados com êxito na aprendizagem, pois proporcionam ao estudante uma maior percepção do que se está sendo estudado. ${ }^{18}$ Outros recursos que contribuem para a aprendizagem desses sujeitos são os tecnológicos. A tecnologia oferece programas que oportunizam a leitura da tela, permitindo ao usuário navegação à internet, entre outras possibilidades. ${ }^{19,20}$ Neste ponto, as escolas esbarram na falta de acesso aos recursos.

A técnica apresentada neste trabalho foi desenvolvida com a utilização da resina de poliéster, um polímero que apresenta baixa viscosidade em condições normais. Esta resina é um composto orgânico, derivado do petróleo e passa do estado líquido para o sólido através de um processo químico chamado polimerização. A consistência final do material depende da adição de um catalisador (peróxido de hidrogênio, sendo importante sublinhar que se trata de um material facilmente encontrado no comercio especializado). ${ }^{21}$ É utilizado para laminação, telhas, cascos de embarcações, carenagens de automóveis e afins. Usado em artesanatos, para 
fabricação de bijuterias, vitrais. É resistente a quedas e impactos, e se riscado, é possível polir a superfície. O resultado final pode ser um bloco cristalino, com possibilidade de se incluir materiais dentro da peça, estabilizando e protegendo-os, ou ainda admite adicionar cargas, como calcitas, pó de mármore, talco, corantes diversos, alterando a aparência final e a densidade da peça. Essa possibilidade permite que a densidade da réplica seja semelhante ao original, dando mais realismo à experiência de manusear a cópia. É um material de baixo custo, fácil acesso e de excelente durabilidade. Vale citar que não exige licenças ou prescrições para a compra. ${ }^{22}$

A resina de poliéster não catalisada se comporta como líquido, de forma que ao endurecer preserva com rigor a forma e a textura do recipiente que ocupa. Caso este recipiente seja o molde de silicone ou gesso de um objeto, uma vez separados, obtém-se uma cópia fiel do objeto que originou este molde. É necessário, portanto, que se tenha um objeto modelo inicial para que seu molde seja feito. Uma vez pronto, o molde pode ser utilizado diversas vezes para replicação com resina. Isto traz vantagem no que diz respeito à diminuição do custo de produção de cada peça. Uma exigência técnica é que seja manipulada em capela de exaustão ou em ambiente bem ventilado, uma vez que durante a cura libera vapores irritantes às vias aéreas.

\section{MATERIAL E MÉTODOS}

\subsection{ESCOLHA DO MATERIAL A SER REPRODUZIDO}

O material escolhido para este trabalho foi o fóssil de um amonita da subclasse Ammonoidea, um molusco cefalópode da escarpa devoniana do estado do Paraná, gentilmente cedido do acervo do Museu de Ciências Naturais - Setor de Ciências Biológicas da Universidade Federal do Paraná pelo seu curador Professor Fernando Sedor. Tal escolha recaiu sobre este fóssil especificamente devido ao relevo da peça, seu tamanho reduzido, e da importância científica deste acervo.

\subsection{CRIAÇÃO DO MOLDE}

Todos os produtos utilizados neste trabalho foram obtidos no comercio varejista de produtos químicos (Casa do Silicone - Curitiba, Paraná).

Para a criação do molde obtido do fóssil original foi utilizada borracha líquida de silicone (Down Corning BX-80o1), sem qualquer tipo de aditivo a não ser o aglutinante (ácido acético $20 \%$ ). O fóssil cuja forma foi copiada em negativo inicialmente foi revestido, em totalidade, com uma camada fina por aspersão de óleo mineral do tipo WD-40, para impedir a aderência da borracha em sua superfície. Para a criação do molde, pode-se utilizar um recipiente plástico com o tamanho e forma aproximados da peça a ser copiada, de modo a acondicionar o fóssil com margens livres de aproximadamente $2 \mathrm{~cm}$, em que será derramada a borracha líquida (Figura 1), previamente misturada a $5 \%$ de aglutinante, até a cobertura total da peça. 


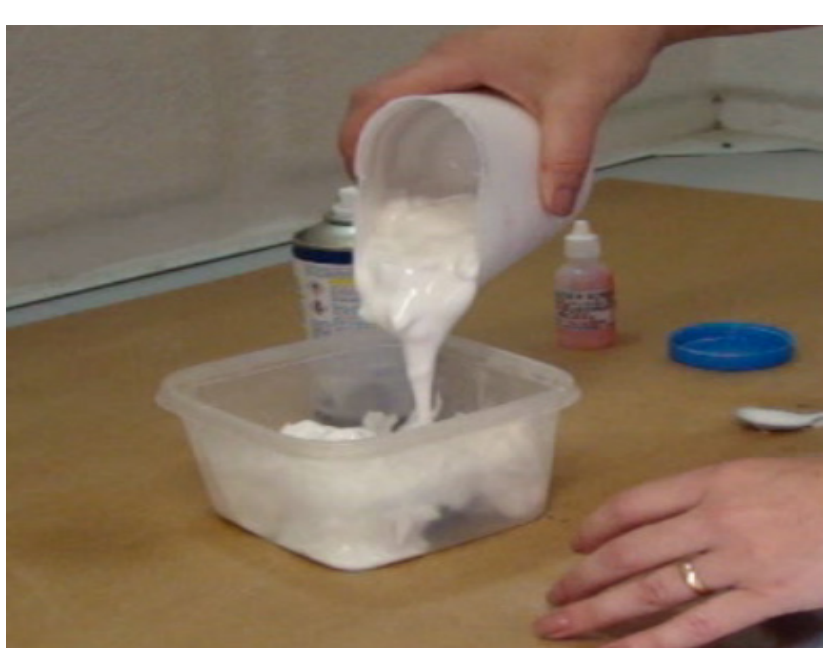

Figura 1 - Confecção do molde do fóssil de amonite da subclasse Ammonoidea utilizando a borracha de silicone.

Foi utilizado uma profundidade mínima de $2 \mathrm{~cm}$, o que garantiu uma resistência ótima ao molde. O uso de cola branca lavável para fixar o verso do fóssil à forma impediu que a peça eventualmente flutuasse. A catálise total ocorre 24 h após a mistura borracha/catalisador.

Uma vez removido da forma temporária (Figura 2A), já foi possível a utilização do molde (Figura 2B), que não requer quaisquer tipos de cuidados especiais, a não ser um manuseio cuidadoso.

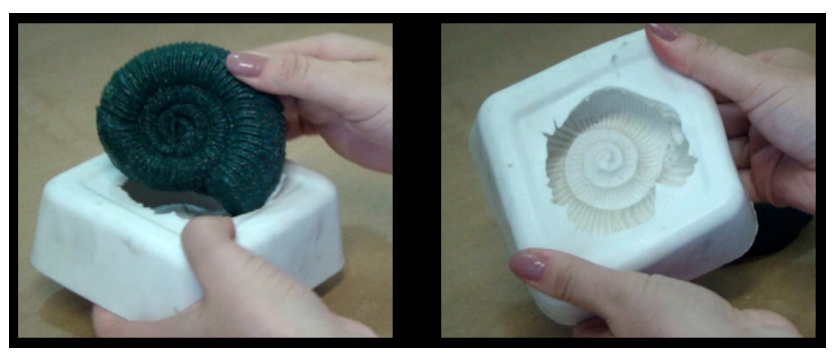

Figura 2 - Desenformação da peça original para obtenção do molde (A) e molde pronto depois de $24 \mathrm{~h}$ após a retirada da peça original (B).

\subsection{PRODUÇÃO DA CÓPIA}

Para a obtenção da cópia da peça original a partir do molde cuja fabricação foi previamente descrita, foi utilizada a seguinte metodologia: levando-se em conta que a resina de poliéster (AOC $\mathrm{C}_{520}-\mathrm{C}$ ) reage com muitos tipos de plástico e que pode atingir temperaturas de até 80 graus durante a cura, deve-se utilizar um frasco de vidro para preparar a mistura que será acondicionada no molde já pronto. A proporção sugerida de resina e carga mineral é de 4 partes de resina de poliéster e 3 partes de pó de mármore. O objetivo é criar um objeto com peso e densidade aproximada do fóssil mineralizado. A homogeneização desta mistura foi feita por meio de espátula e ação manual. Durante este processo se adiciona o catalisador, na proporção de $1 \%$ (peróxido de hidrogênio 20\%). Caso se deseje, é possível colorir a mistura com pigmentos solúveis em derivados de petróleo. A mistura permaneceu líquida por um período de aproximadamente 10 minutos, no qual a forma foi preenchida até seu limite superior com esta mistura (Figura 3A). No período de aproximadamente 3 horas é possível retirar a cópia da forma, mas esta deve ser tratada com gentileza, uma vez que a cura total leva aproximadamente 72 horas. Neste ponto é obtida uma cópia fiel do fóssil original (Figura 3B).

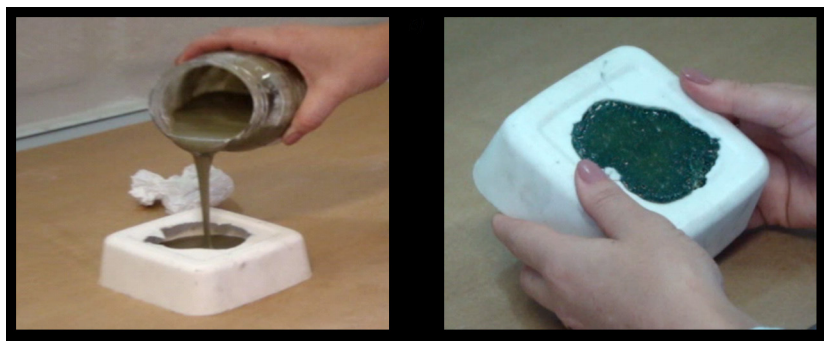

Figura 3 - Despejo da resina de poliéster ainda líquida, no molde de silicone $(\mathrm{A})$ e a réplica em resina de poliéster pronta, após 24 horas (B). 


\subsection{ALFABETO BRAILLE}

De acordo com a Figura 4A, a numeração em Braille foi possível de ser executada pois existe um programa no computador em que se pode baixar a fonte em Alfabeto Braille, para o editor de textos Word. A fonte foi obtida por download no endereço: http://intervox.nce.ufrj.br/ brailu/ downloads.html.

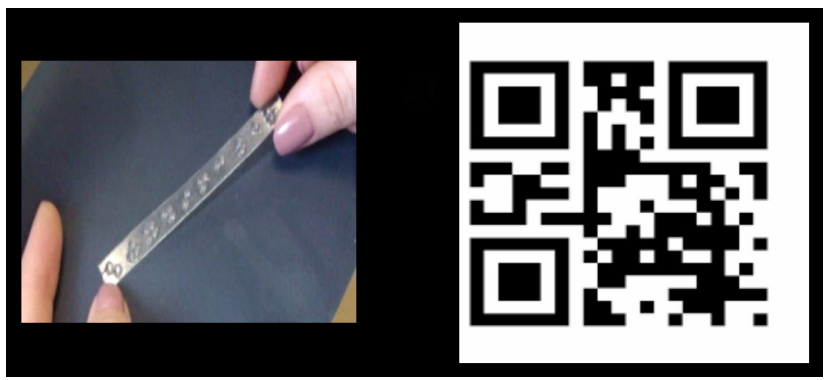

Figura 4 - Números de o (zero) a 9 (nove) em Braille feito com carimbo (A) e modelo de um QR-Code indicando o canal do YouTube ao qual o é direcionado (B). Página de downloads. ${ }^{23}$

Além disso, foi tomado o cuidado de obter a fonte de um site mantido por uma instituição de ensino brasileira de renome, garantido o rigor nesta codificação. Esta, que foi adicionada à textura do fóssil e na placa em que constava o $Q R$-Code, (Figura $4 \mathrm{~B}$ ) foi obtida em uma fábrica de carimbos a partir da fonte supracitada. Apesar de ser possível obter o Alfabeto Braille em aço, em empresas de comunicação visual o custo se mostra proibitivo, sendo esta possibilidade descartada. Letras em Braille, em papel ou papelão, perdem sua textura no processo de criação do molde e com o uso, inútil, portanto, para a nossa finalidade, então, a alternativa mais econômica foi encomendar em uma fábrica de carimbos as letras ou os números utilizados. A textura deste processo é muito próxima do ideal para a leitura pelo tato.
O tamanho de cada número foi de $0,5 \mathrm{~cm} \times 0,5 \mathrm{~cm}$. $\mathrm{O}$ único cuidado a ser tomado é que normalmente carimbos contam com gravação especular em sua parte emborrachada, e neste caso a gravação não pode ser espelhada, pois o que será lido não é a impressão do carimbo, mas o carimbo em si.

\subsection{PLACA DIRECIONADORA}

Para que o estudante tenha acesso às narrações referentes ao objeto de análise, foi utilizado uma prancheta de acrílico de tamanho $\mathrm{A}_{4}$ e $3 \mathrm{~mm}$ de espessura. É um material de fácil acesso, podendo ser adquirida em papelarias a preço baixo. De acordo com a Figura 8A, à esquerda, com cola branca comum, foi feita a fixação da numeração em Braille, destacada um a um do carimbo, o que permite que se relacionem as subestruturas indicadas no fóssil. Cada número é seguido por uma trilha que pode ser feita de duas formas: em baixo relevo, onde se utiliza um objeto pontiagudo para riscar o acrílico, ou em alto relevo feita com cola branca. Esta trilha tátil direciona o estudante a uma moldura quadrada de $5 \times 5 \mathrm{~cm}$, também em relevo, feita com a mesma cola. Esta moldura delimita um QR-Code (Figura 5B). 


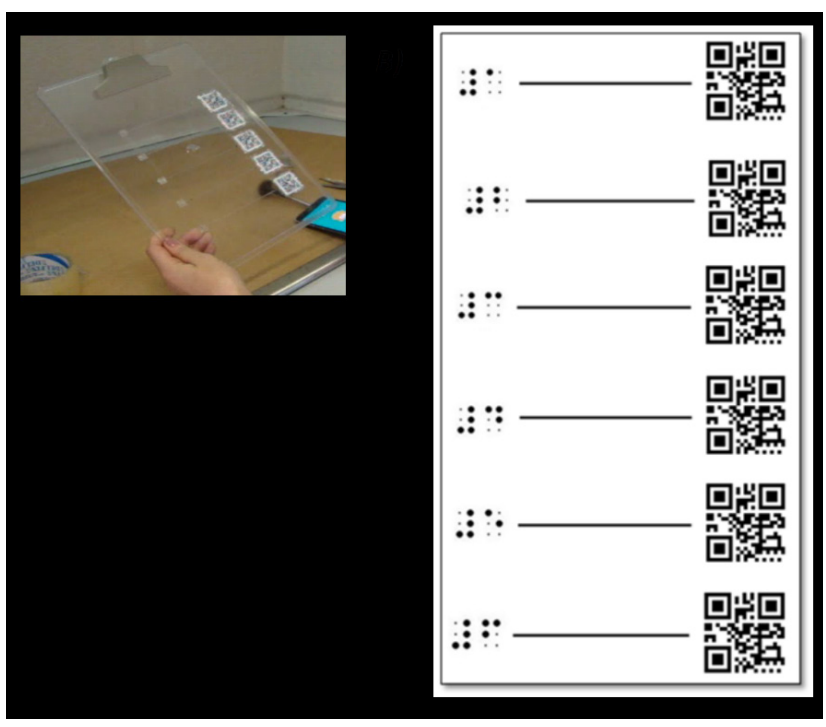

Figura 5 - Modelo pronto de placa direcionadora para QRCode (A) e proposta de placa direcionadora desenvolvida nesta metodologia (B).

Neste contexto, a decisão de utilizar o um $Q R$-Code foi baseada em alguns elementos. $\mathrm{O}$ mais importante foi minimizar o uso do Alfabeto Braille, que depende de impressão em relevo, neste caso em silicone, que geraria um custo adicional. Ao indicar um código que direciona o estudante a uma narração, é indicado eliminar textos em Braille, permitindo que indivíduos que não dominem este tipo de leitura se beneficiem do método. Adicionalmente, se a placa direcionadora já contivesse o nome da estrutura, ela se tornaria exclusiva da peça a ser estudada. Uma vez substituído o $Q R$-Code da placa, um novo conteúdo é adicionado, mas a placa é reutilizada, conferindo mais uma medida de economia de recursos, e também uma forma de se poupar espaço de armazenamento de material.

Cada uma das subestruturas de interesse didático no objeto original recebeu um número do Alfabeto Braille, que foi adicionado à textura do fóssil. Essa numeração - que pode ser obtida em uma fábrica de carimbos - deve ser colada nas regiões de interesse com cola branca lavável, assim sendo facilmente retirada do original. Este relevo é incorporado definitivamente ao molde e, consequentemente, a todas as copias que se originarem.

\section{6 ÁUDIO POR QR-CODE}

$\mathrm{O} Q R$-Code se baseia em um código de barras em $2 \mathrm{D}$ que tem o intuito de ser escaneado e conduzir a algum tipo de informação, como um texto, link, foto, ou qualquer outro tipo de dado que possa ser publicado na Internet. Para ler o $Q R$ Code e ter acesso à sua informação, é necessária a utilização de um celular que contenha um aplicativo específico.

Para obter o código, deve-se usar um programa ou aplicativo no computador ou no celular, e então vincular o link do vídeo com a descrição da peça ou da estrutura desejada, previamente gravados pelo docente. Nota-se que o mesmo material pode ser utilizado por estudantes em diferentes níveis, variando o conteúdo da gravação e substituindo o $Q R$-Code da placa. Cada número em Braille deve ser representado por um $Q R$-Code que indica a estrutura e contém explicações determinadas sobre a região em questão.

Assim, foram gravados, utilizandogravador de voz de um celular Samsung J-5, as indicações e explicações sobre o material em questão, para as seis partes numeradas no material. Os áudios foram convertidos para vídeos e lançados no site do Youtube (www.youtube.com), para onde são direcionados quando os $Q R$-Codes forem lidos. 


\section{RESULTADOS}

Este trabalho teve como objetivo criar um modelo de material didático que fosse de baixo custo e alta durabilidade, além de desenvolver uma metodologia que atendesse às necessidades especiais dos estudantes com deficiência visual, ampliando as possibilidades de recursos tiflológicos disponíveis a esses estudantes e, em análise rigorosa, estes objetivos foram atingidos em sua totalidade.

Esse material pode ser utilizado e aproveitado por estudantes videntes também, ampliando o uso da metodologia. Também é importante ressaltar que a mesma técnica pode ser utilizada na produção de modelos didáticos de baixo custo e alta durabilidade em outras áreas da biologia ou mesmo em outras disciplinas.

O molde pode ser utilizado para produzir a mesma peça inúmeras vezes, podendo ser distribuído ou mesmo comercializado para outras escolas e organizações. Quando não for mais utilizado, pode ser triturado e reutilizado sendo acrescentado a uma nova mistura de silicone líquido. A aquisição dos materiais é de fácil acesso e manuseio. $\mathrm{O}$ projeto realizado buscou como confeccionar a peça, especifica as medidas de todos os ingredientes, tempos de cura e como conseguir o Alfabeto em Braille de uma forma com baixo custo.

Finalmente, o uso do $Q R$-Code proporciona ao estudante uma maior autonomia ao manusear o material. Ele mesmo pode, ao seu ritmo, conhecer a peça, perceber os detalhes da estrutura e ouvir a gravação, quantas vezes for necessário.

\section{DISCUSSÃO}

Dados do último Censo Oftalmológico, ${ }^{2}$ apontam que 90\% dos casos de deficiência visual se concentram em regiões de média e baixa renda, o que torna necessária a produção de material didático inclusivo de baixo custo e fácil acesso, como o proposto em neste trabalho.

Também é importante ressaltar que existe uma grande diversidade quanto ao aspecto da discapacidade visual vivenciada pelos estudantes considerados cegos, portanto, a diversidade de objetos tiflológicos se faz necessária ante ao direito à informação e comunicação. Com a computação, um enorme leque de possibilidades se abriu na educação, não só de videntes mas também, de estudantes cegos. Porém, é necessário que a computação seja associada a ferramentas de acessibilidade, o que buscou-se conciliar nesta metodologia proposta e, que também não seja um fim em sim mesma, mas, um instrumento de aprendizagem a partir de uma perspectiva construtivista-interacionista.

Obviamente a total falta de visão ou mesmo a baixa visão constituem um grande bloqueio na aprendizagem, mas diversos estudos, como os apontados por Sternberb (2000), ressaltam a importância dos demais sentidos, como tato, olfato, audição e percepção háptica na aprendizagem. Quanto mais estímulos forem despertados, no estudante deficiente visual, melhor será a percepção do espaço e dos objetos e menor será a supervalorização da visão e o impacto de sua ausência. ${ }^{24}$ Sendo assim, o docente pode se utilizar de várias estratégias de ensino para seus alunos, utilizando as peças como incentivo didático, pois todos poderão manusear a peça, não ficando restrita apenas aos estudantes deficientes visuais. A manipulação de modelos didáticos 
reforça interações que exercitem o conhecimento adquirido, desperta interesse e favorece $o$ desenvolvimento de competências e habilidade..$^{25}$

Uma revisão bibliográfica mostra que existem poucos trabalhos na área da produção de materiais didáticos para estudantes deficientes visuais, sendo o foco destes trabalhos a utilização do tato como via de acesso à informação. ${ }^{26-28}$ Dentre os recursos mais utilizados na educação de estudantes deficientes visuais está a escrita em Braille. O sistema de leitura e escrita desenvolvido por Louis Braille no século XIX permitiu, com muita eficiência, a substituição da palavra impressa, sendo o maior avanço na educação de deficientes visuais. Porém, estudos como o de Santos, ${ }^{29}$ mostram que a utilização desse sistema tem diminuído no Brasil e alguns fatores podem ser apontados como responsáveis: o volume ocupado pelo material produzido, a dificuldade de transcrição em disciplinas como matemática e química e a perda de sensibilidade nos dedos decorrente de algumas doenças. A ausência de políticas efetivas para a produção e distribuição de material didático em Braille, o alto custo de produção desses materiais e a falta de capacitação de professores nessa área também podem ser adicionados a essa lista..$^{30}$ Portanto nos propusemos a utilizar a escrita em Braille de forma reduzida e não como via principal de veiculação da informação.

\section{CONCLUSÃO}

O produto final obtido por esta pesquisa mostrou-se promissor e apto a ser testado por estudantes com diferentes graus de deficiência visual, apresentando baixo custo, fácil produção, segurança no manuseio e produção. O seu uso foi bastante simples e o $Q R$-Code direcionou o usuário a narração na plataforma YouTube de forma bastante consistente. Se comparado aos métodos tradicionais de estudo para cegos, é bastante competitivo do ponto de vista econômico e tem a grande vantagem de ser portátil, reduzindo o grande volume gerado pelo Braille e, mesmo que ocorram perdas ou danos ao material, sua reposição é simples e barata.

\section{REFERÊNCIAS}

1. Universidade Federal do Recôncavo da Bahia. Orientações para professores de estudantes cegos. Ministério da Educação. Núcleo de Políticas de Inclusão [Internet]. 2012 [acesso em 2019 abr 12 ]. Disponível em: https://www.ufrb.edu.br/nupi/images/documentos/Orientaes\%2opara\%2oprofessores\%2ode\%2oEstudantes\%2oCegos.pdf

2. Instituto Brasileiro de Geografia e Estatística. Censo Demográfico 2010: Características Gerais da População, religião e pessoas com deficiência [Internet]. Rio de Janeiro: IBGE; 2010. [acesso em 2019 maio 8]. Disponível em: https://biblioteca.ibge.gov.br/visualizacao/periodicos/94/cd_2010_religiao_deficiencia.pdf

3. Conselho Brasileiro de Oftalmologia. Censo oftalmológico: As condições de saúde ocular no Brasil [Internet]. São Paulo: CBO; 2019. [acesso em 2020 jul 14]. Disponível em: www.cbo.com.br/novo/ publicacoes/condicoes_saude_ocular_brasil2019.pdf 
4. Ormelezi EM. Inclusão educacional e escolar da criança cega congênita com problemas na constituição subjetiva no desenvolvimento global: uma leitura psicanalítica em estudos de caso [tese de doutorado]. [São Paulo]: Universidade de São Paulo; 2006.

5. Brito PR, Veitzman S. Causas de cegueira e baixa visão em crianças. Arq. Bras. Oftamol. [Internet]. $2000 \mathrm{fev}$ [acesso em 2019 maio 8];63(1):49-54. Disponível em: https://www.scielo.br/pdf/abo/ v63n1/13605.pdf

6. Almeida TS, Araújo FV. Diferenças experienciais entre pessoas com cegueira congênita e adquirida: uma breve apreciação. Rev. Interfaces [Internet]. 2013 Jun [acesso em 2019 maio 8];1(3):1-21. Disponível em: https://interfaces.leaosampaio.edu.br/index.php/revista-interfaces/article/ view/24/o.

7. Silva, LGS. Orientações para atuação pedagógica junto a estudantes com deficiência visual. Orientações para atuação pedagógica junto a estudantes com deficiência: intelectual, auditiva, visual, física. Natal: WP Editora; 2010.

8. Lima EC. A inclusão da criança com deficiência visual na escola regular [Internet]. 2016 maio [acesso em 2019 maio 8]. Disponível em: https://www.fundacaodorina.org.br/blog/artigo-a-inclusao-da-crianca-com-deficiencia-visual-na-escola-regular/.

9. Glat R, Ferreira, JR. Panorama Nacional da Educação Inclusiva no Brasil: Relatório de consultoria técnica. In: Banco Mundial [Internet]. 2003 [acesso em 2020 jul]. Disponível em: https://repositorio.ipsantarem.pt/bitstream/10400.15/1626/1/SG_Disserta\%c3\%a7\%c3\%a30\%20ANA\%20 LEAL\%20.pdf

10. Nunes S, Lomônaco JFB. O estudante cego: preconceitos e potencialidades. Rev. Semestral da Associação Brasileira de Psicol. Esc. Educ. [Internet]. 2010 jan-jun [acesso em 2019 maio 8];4(1):55-64. Disponível em: https://www.scielo.br/pdf/pee/v14nı/v14nıao6

11. Silva AVF, Rodrigues RDR. Confecção e utilização de materiais didáticos em resina para deficientes visuais no ensino de ciências e biologia [trabalho de conclusão de curso de graduação]. [Curitiba]: Universidade Federal do Paraná; 2016.

12. Roveda PA. Aprendendo a ver: possibilidade do trabalho pedagógico para o desenvolvimento da eficiência visual em bebês com baixa visão. In: Anais do Décimo terceiro Seminário Internacional de Educação. Agosto 16-18, 2012. Novo Hamburgo; 2012. [acesso em 2019 abr 19]. Disponível em: https://www.feevale.br/Comum/midias/2bc24ffo-cob9-4597-b874-c425028ecceg/APRENDENDO\%20A\%2oVER\%20-\%2oPOSSIBILIDADES\%2oDO\%20TRABALHO\%2oPEDAG\%C3\%93GICO\%2oPARA\%20O\%20.pdf

13. Bruno MM. O desenvolvimento integral do portador de deficiência visual - Da intervenção precoce à integração escolar. São Paulo: Laramara; 1993. 
14. Gil M. Deficiência Visual [Internet]. Brasília, DF: MEC: Secretaria de Educação à Distância; 2000;(Cadernos da TV Escola, no. 1). [acesso em 2019 mar 15]. Disponível em: portal.mec.gov.br/ seed/arquivos/pdf/deficienciavisual.pdf

15. Laplane ALF, Batista CG. Um estudo das concepções de professores de ensino fundamental e médio sobre aquisição de conceitos, aprendizagem e deficiência visual. In: Anais do Primeiro Congresso Brasileiro de Educação Especial. Novembro 11-14, 2003. São Carlos; 2003. p. 14-15.

16. Santos V. Aulas de Biologia para Deficientes Visuais [Internet]. Brasil Escola. Disponível em: https://educador.brasilescola.uol.com.br/estrategias-ensino/aulas-biologia-para-deficientes-visuais.htm. [acesso em 2018 abr 12].

17. Cerqueira JB, Ferreira EMB. Recursos didáticos na educação especial. Rev. Benjamim Constant. 2000;6(15):24-8.

18. Masini EFS. O perceber e o relacionar-se do deficiente visual: orientando professores especializados. Boletim Anped. 1991 jan-dez;143-4.

19. Orlando TC, Lima AR, Silva AM, Fuzissaki CN, Ramos CL, Machado D, et al. Planejamento, montagem e aplicação de modelos didáticos para abordagem de biologia celular e molecular no ensino médio por graduandos de Ciências Biológicas. Rev. Ensino Bioquím. 2009;7(1):1-17.

20. Rupell DT, Mendonça MH, Schadeck RJ. Célula 3D: um recurso didático virtual interativo. In: Décimo segundo Congresso Nacional de Educação. Outubro 26-29, 2015. Curitiba; 2015. [acesso em 2019 maio 8]. Disponível em: https://educere.bruc.com.br/arquivo/pdf2015/21596_9662.pdf

21. Redelease. 7 dicas para trabalhar com resina poliéster [Internet]. 2017 [acesso em 2019 maio 9]. Disponível em: https://www.youtube.com/watch?v=U4A8BcXq19s

22. Faz Fácil Artesanato. Resinas e a Resina de Poliéster [Internet]. [acesso em 2019 maio 9]. Disponível em: https://www.fazfacil.com.br/artesanato/resinas-poliester-epoxi/

23. Página de Downloads [Internet]. [acesso em 2019 maio 9]. Disponível em: http://intervox.nce.ufrj. br/ brailu/downloads.html

24. Sternberg RJ. Psicologia Cognitiva. 5a ed. Porto Alegre: Cengage CTP; 2000.

25. Bustos CMS, Fedrizzi B, Guimarães LBM. Percepção dos deficientes visuais: cores x texturas. In: Anais da Primeira Conferência Latino-Americana de construção sustentável; Décimo Encontro Nacional de Tecnologia do Ambiente Construído. Julho 18-21, 2004. São Paulo: ANTAC; 2004. [acesso em 2020 jul 14]. Disponível em: http://www.producao.ufrgs.br/arquivos/publicacoes/111_ deficientes\%2ovisuais.pdf 
26. Figueiredo RME, Kato OM. Estudos Nacionais Sobre o Ensino para Cegos: uma Revisão Bibliográfica [Internet]. 2015 [acesso em 2020 ago 17]. Disponível em: file:///C:/Users/Professores/Downloads/revisa $\% \mathrm{C}_{3} \% \mathrm{~B}_{5} \% 2$ ometodos.pdf

27. Fernandes SHAA, Healy L. A inclusão de estudantes cegos nas aulas de matemática: explorando área, perímetro e volume através do tato. BOLEMA. 2010;23(37):1111-35.

28. Zucherato B, Freitas MIC. A construção de gráficos táteis para estudantes deficientes visuais. Rev. Ciênc. Ext. 2011;7(1):24-41.

29. Santos JAB. Do Braille ao Dosvox: diferenças nas vidas dos cegos brasileiros [tese] [Internet]. Rio de Janeiro: Universidade Federal do Rio de Janeiro; 200. [acesso em 2020 jul 13]. Disponível em: file://C:/Users/Professores/Downloads/5617-18773-1-PB.pdf

30. Barbosa LMM, Silva AL, Souza MA. O sistema Braille e a formação do professor: o acesso à leitura e a escrita por pessoas cegas. Rev. InFor. [Internet]. 2019 Nov [acesso em 2020 jul 13];5(1):49-71. Disponível em: https://infor.ead.unesp.br/index.php/nead/article/view/InFor4603v5n12019 
